\title{
Corrigendum to "The Role of Descending Modulation in Manual Therapy and Its Analgesic Implications: A Narrative Review"
}

\author{
Andrew D. Vigotsky ${ }^{1}$ and Ryan P. Bruhns ${ }^{2}$ \\ ${ }^{1}$ Kinesiology Program, Arizona State University, Phoenix, AZ 85004, USA \\ ${ }^{2}$ College of Medicine, University of Arizona, Tucson, AZ 85724, USA \\ Correspondence should be addressed to Andrew D. Vigotsky; avigotsk@asu.edu \\ Received 21 August 2017; Accepted 27 September 2017; Published 26 October 2017 \\ Copyright (C) 2017 Andrew D. Vigotsky and Ryan P. Bruhns. This is an open access article distributed under the Creative Commons \\ Attribution License, which permits unrestricted use, distribution, and reproduction in any medium, provided the original work is \\ properly cited.
}

In the article titled "The Role of Descending Modulation in Manual Therapy and Its Analgesic Implications: A Narrative Review" [1], there was an error in the interpretation of the data presented by Plaza-Manzano et al. (2014). Therefore, in the Spinal Manipulation section, the sentence "Both cervical and thoracic groups saw decreases in neurotensin and oxytocin, as well as increases in orexin A plasma concentrations following respective interventions" should be corrected to "Both cervical and thoracic groups saw increases in neurotensin and oxytocin, as well as decreases in orexin A plasma concentrations following respective interventions."

Additionally, in the Conclusion section, the text reading "Nearly all types of manual therapy have been shown to elicit a neurophysiological response that is associated with the descending pain modulation circuit; however, it appears that different types of manual therapy work through different mechanisms (Table 1). For example, while massage therapy appears to elicit an oxytocin response, spinal manipulation does not. It is crucial that more higher quality research be performed to better understand these mechanisms, as it can lead to a better understanding of how each therapy can be applied to drive more specific clinical research" should be corrected as follows.

"Nearly all types of manual therapy have been shown to elicit a neurophysiological response that is associated with the descending pain modulation circuit; however, it appears that potential analgesic responses to different types of manual therapy may be modulated by different mechanisms (Table 1). For example, while osteopathic manipulative therapy appears to elicit a $\beta$-endorphin response, conventional massage does not. It is crucial that higher quality research with better controls be carried out to better understand potential mechanisms, as this will lead to a better understanding of how each therapy may be applied to drive more specific clinical research."

Finally, Table 1 should be corrected as follows. 


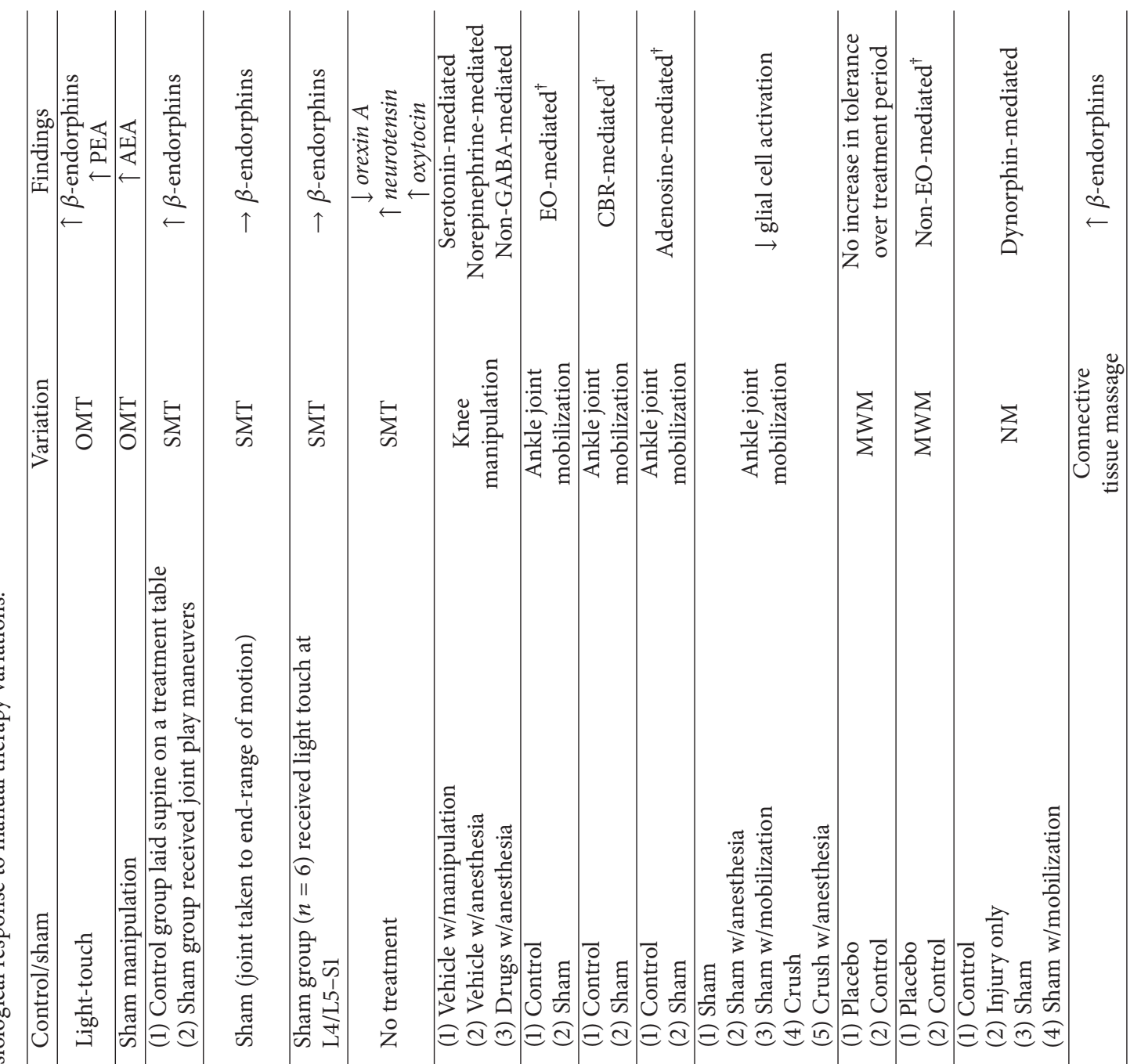

言 z

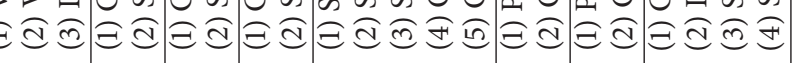

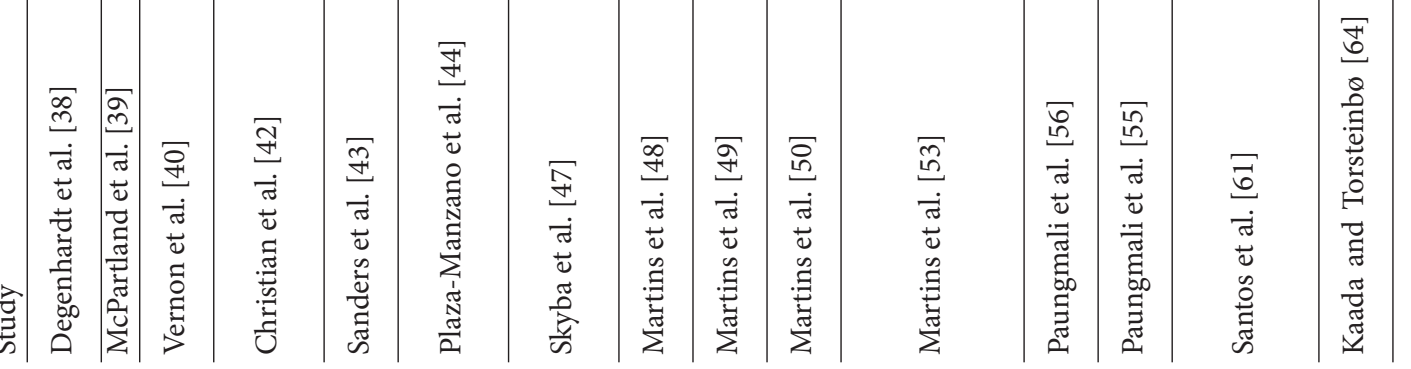




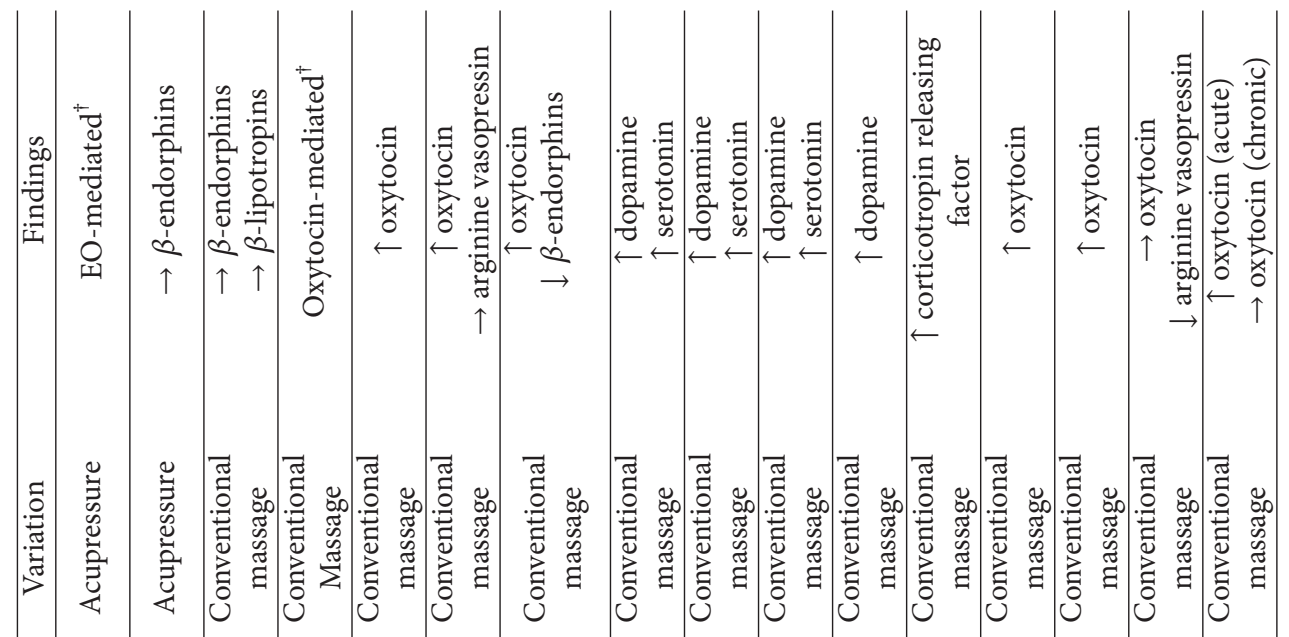

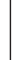

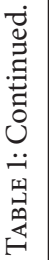

苟

类

这

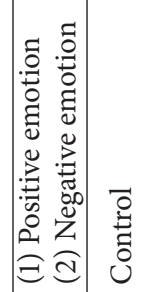

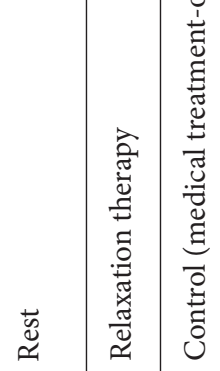

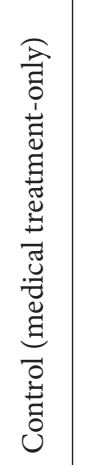

좋

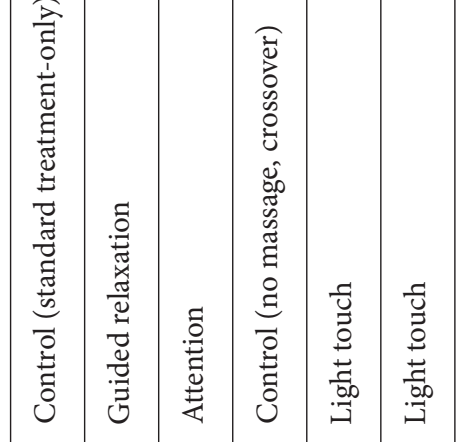

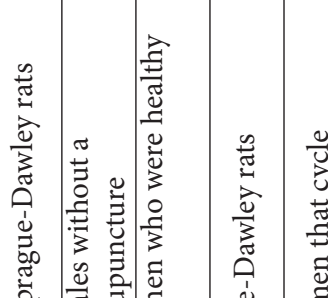

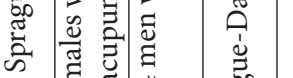

苟

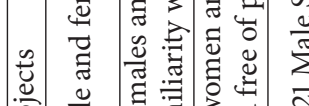

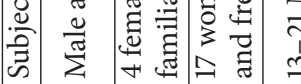

당

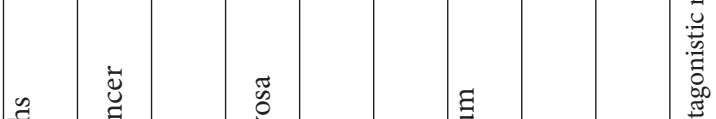

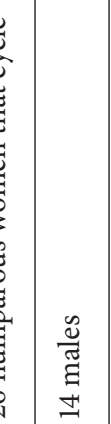

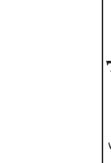

志

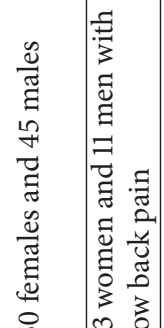

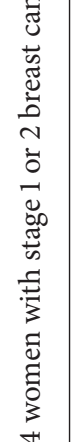

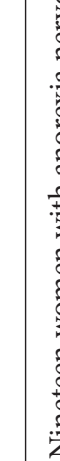

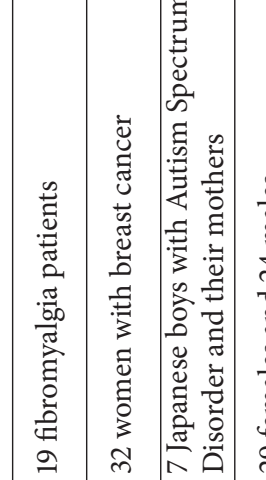

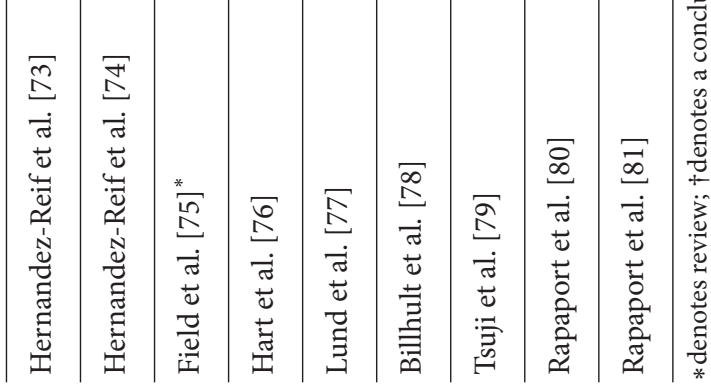




\section{References}

[1] A. D. Vigotsky and R. P. Bruhns, "The role of descending modulation in manual therapy and its analgesic implications: a narrative review," Pain Research \& Management, vol. 2015, Article ID 292805, 11 pages, 2015. 


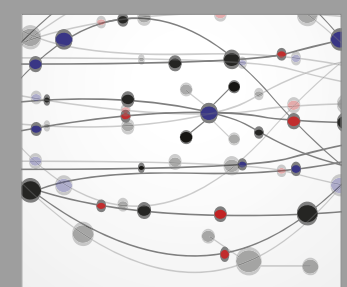

The Scientific World Journal
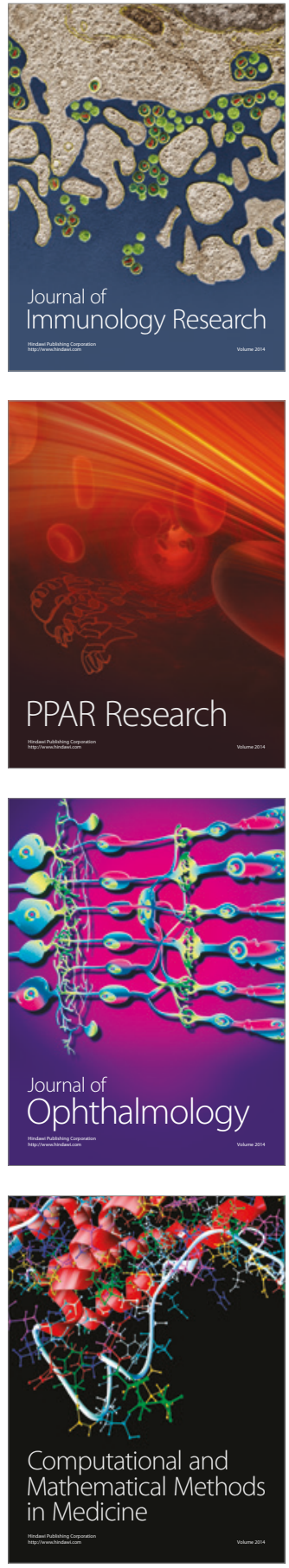

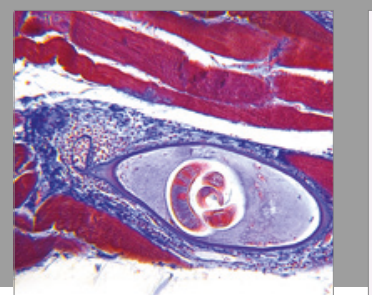

Gastroenterology Research and Practice
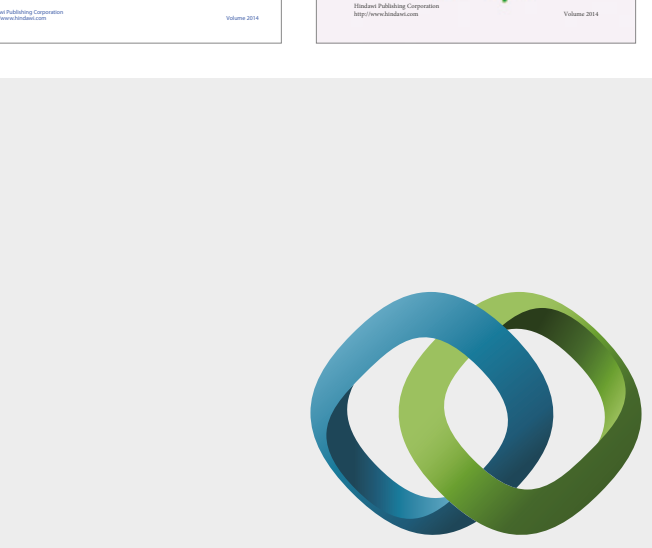

\section{Hindawi}

Submit your manuscripts at

https://www.hindawi.com
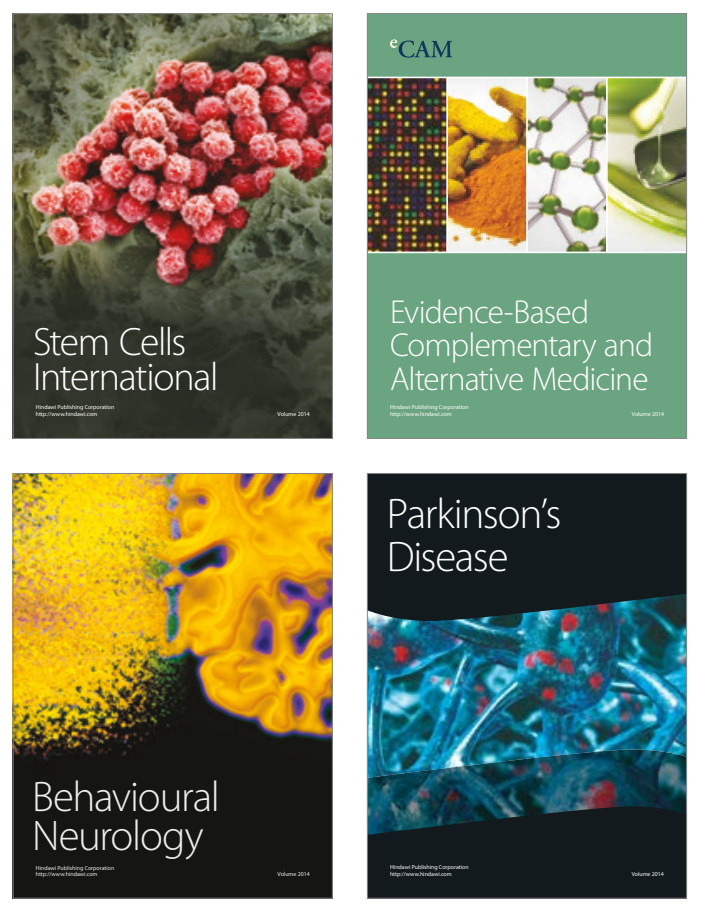
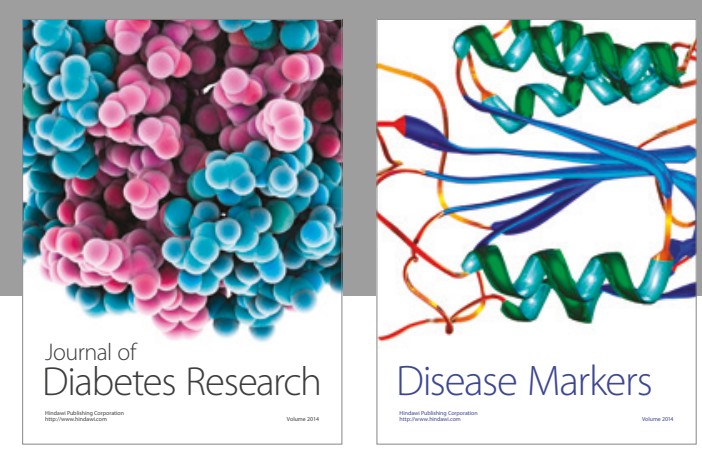

Disease Markers
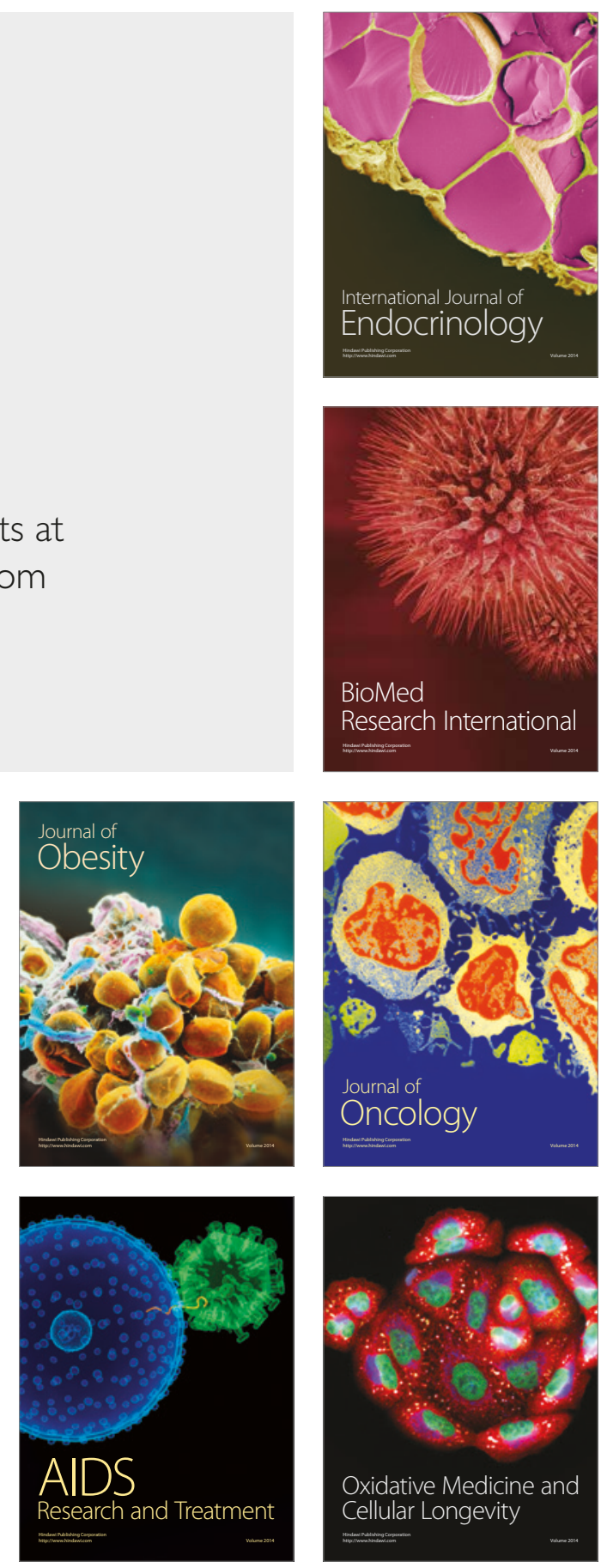